\title{
On the development of educational content on the subject "Fundamentals of Mathematical Informatics" for future bachelors of computer science Sadulaeva B. ${ }^{1}$, Mustafinova A. ${ }^{2}$ (Russian Federation) О разработке содержания образования по дисциплине «Основы математической информатики» для будущих бакалавров информатики Садулаева Б.С.1, Мустафинова А.А.2 (Российская Федерация)
}

\author{
${ }^{I}$ Садулаева Билянт Султановна / Sadulaeva Bilyant Sultanovnа - кандидат педагогических наук, доиент; \\ ${ }^{2}$ Мустафинова Аза Александровна / Mustafinova Aza Alexandrovna - cmариий преподаватель, \\ кафедра прикладной математики и механики \\ Чеченский государственный университет, г. Грозный
}

\begin{abstract}
Аннотация: в статье представлен алгоритм проектирования содержания образования будущих бакалавров информатики с использованием икалированной модели владения базовыми математическими понятиями при изучении дисциплин профильной подготовки, трансформированной системы взаимоувязанных матрии (предложенной В. П. Пустобаевым), матрицы определения «веса» компетенций и «веса» элементов содержательных линий математической информатики, а также метода топологической сортировки.
\end{abstract}

Abstract: the article presents an algorithm for the design of educational content for future bachelors of computer science with the scaled model of ownership basic mathematical concepts in the study of disciplines profile preparation, transformed system of interconnected matrices (proposed Pustobaevym VP), a matrix determining the "weight" of competences and the "weight" of the elements of substantial lines mathematical Informatics and topological sorting method.

Ключевые слова: разработка содержания образования, математическая информатика, матрица компетеничй, матрица «веса» компетенциий.

Keywords: the development of educational content, mathematical science, competence matrix, the matrix of the "weight" of competencies.

В соответствии с этапами проектирования методической системы обучения математической информатике будущих бакалавров информатики, предложенной автором в исследовании [9], проектирование компетентностно-ориентированного содержания образования предполагает прогнозирование компетенций и постановку диагностичных целей обучения, в соответствии с намеченными компетенциями.

Согласно С. И. Архангельскому [1], Т. А. Бороненко [3], М. Д. Даммер [4] за определением целей и ожидаемых результатов обучения (прогнозирование компетенций) определяется технология установления междисциплинарных связей, технология отбора содержания обучения, методов, форм и средств обучения.

При отборе содержания учитывалась технология профессиональной направленности изучения предспециальных учебных дисциплин, предложенная В. И. Земцовой [5], (для профессиональной направленности личности студента технических специальностей).

К вышеуказанным направлениям необходимо добавить фундаментальность образования в области математической информатики [8], которая обеспечивает:

- системный уровень познания действительности, способности видеть и понимать основы интеграции математических и информатических наук;

- формирование существенных, устойчивых знаний, лежащих в основе научного объяснения теоретических и практических задач информатики;

- создание когнитивной базы профессиональной культуры и профессионального мастерства и т.д.

Также учтены структура, содержание, ядро базовых знаний, рекомендованные для международной образовательной системы подготовки бакалавров ИТ, согласно которым в «состав курса математики ввести модуль Дискретные структуры» [11].

Для определения содержания образования, кроме трех условий, предложенных В. В. Краевским, необходимо выполнение условия - специалист каждого нового выпуска должен обладать набором определенных компетенций и уметь применять полученные знания, в своей будущей педагогической деятельности, в новых постоянно изменяющихся и прогрессирующих условиях [9].

Четвертое условие характеризует профессиональную компетентность выпускника, В. В. Сухомлин [10] определяет ее как исходную компетенцию.

Построение логической структуры курса требует выделения разделов (тем) и соответствующих им учебных элементов. 
В целях определения «веса» выделенных математических компонентов информатики создана экспертная группа преподавателей профильных дисциплин информатики, которые ограничились упорядоченной шестибалльной шкалой со значениями от «0» до «5».

Таким образом, проектируем шкалированную модель владения базовыми математическими понятиями при изучении дисциплин профильной подготовки

Для моделирования содержания математической информатики использована трансформированная система взаимоувязанных матриц, предложенная В. П. Пустобаевым [7].

Система взаимоувязанных матриц В. П. Пустобаева позволяет описать связи между перечнем профессионально-педагогическими компетенциями будущих бакалавров информатики и разделами математики, связи между дисциплинами профильной подготовки и разделами математических основ информатики.

По результатам экспертной оценки (20 человек) выявлены наиболее значимые темы курса «Основы математической информатики».

Для объединения тем в смысловые группы воспользовались программой, реализующей модифицированный алгоритм топологической сортировки.

Интерпретируя результат, получим перечень блоков тем, приведенных в таблице 1.

Методом топологической сортировки тем содержания установлена последовательность их изучения [6].

Таблица 1. Ранжирование тем курса «Основы математической информатики»

\begin{tabular}{|c|c|c|}
\hline • & Математические разделы, понятия & $\begin{array}{l}\text { Последующие } \\
\text { темы }\end{array}$ \\
\hline 1 & $\begin{array}{l}\text { Множества, операции на множествах. Дискретное множество. Счетное } \\
\text { множество. Разрешимые и перечислимые множества. }\end{array}$ & $\begin{array}{l}2,3,5,6,8 \\
9,16,33\end{array}$ \\
\hline 2 & Прямое произведение множеств, кортеж & $5,14,23$, \\
\hline 3 & $\begin{array}{l}\text { Теория чисел, простое число, арифметические действия над числами, } \\
\text { признаки делимости числа, Системы счисления }\end{array}$ & $10,19,23$ \\
\hline 4 & Производящие функции & 31 \\
\hline 5 & Отношения на множествах & \\
\hline 6 & Подстановки, элементы комбинаторики & $11,20,16,17,22$ \\
\hline 7 & $\begin{array}{l}\text { Логика предикатов. Логика высказываний. Логические связки и составные } \\
\text { высказывания. Таблицы истинности }\end{array}$ & 13,8 \\
\hline 8 & Методы доказательств. Метод математической индукции & 12 , \\
\hline 9 & Функции, отображения. Вызов функции, объявление функции. & $10,12,18,30,31$ \\
\hline 10 & Целочисленные функции. Невычислимые функции. & 18 , \\
\hline 11 & Оператор, композиция операторов, оператор цикла & 9 , \\
\hline 12 & Рекурсивные функции, частично рекурсивные функции, & $10,11,17$ \\
\hline 13 & Булева алгебра, система булевых функций & $7,2,5,6$ \\
\hline 14 & Матрицы, СЛУ & $15,21,28,29,24$ \\
\hline 15 & Векторы & $24,28,29$ \\
\hline 16 & Направленное множество - цепи & 17,12 \\
\hline 17 & Графы, деревья & 20,16 , \\
\hline 18 & Алгоритмы аппроксимации числовых функций & 25 \\
\hline 19 & Элементы компьютерной алгебры, полиномы & 12,4 \\
\hline 20 & Задачи и методы дискретной математики & 17 , \\
\hline 21 & Задачи линейного программирования & 14,15, \\
\hline 22 & Элементы теории вероятностей & $25,26,27$ \\
\hline 23 & Алгоритм Евклида, & 16,17 \\
\hline 24 & Геометрическое моделирование и компьютерная графика & Нет \\
\hline 25 & $\begin{array}{l}\text { Численный эксперимент. Достоверность численной модели. эмпирические } \\
\text { измерения эффективности алгоритмов }\end{array}$ & Нет \\
\hline 26 & $\begin{array}{l}\text { Дискретная и непрерывная случайные величины, закон распределения } \\
\text { случайной величины }\end{array}$ & 20,27 \\
\hline 27 & Элементы теории массового обслуживания & Нет \\
\hline 28 & Уравнение прямой, кривые и поверхности второго порядка & 24 \\
\hline 29 & Уравнение плоскости, прямая и плоскость & 24 \\
\hline 30 & Элементы дифференциального исчисления. Разностный оператор & 31 , \\
\hline
\end{tabular}




\begin{tabular}{|l|l|l|}
\hline 31 & Элементы интегрального исчисления. Интегральный оператор & 34, \\
\hline 32 & Сумма, действие над суммами & 30,31, \\
\hline 33 & Последовательность, ряды & 32,35 \\
\hline 34 & Дифференциальные уравнения & Нет \\
\hline
\end{tabular}

На рисунке 1 представлен график, отображающий последовательность изучения тем, полученную методом топологической сортировки.

Из отобранного материала составлена программа по курсу «Основы математической информатики» в модульной форме.

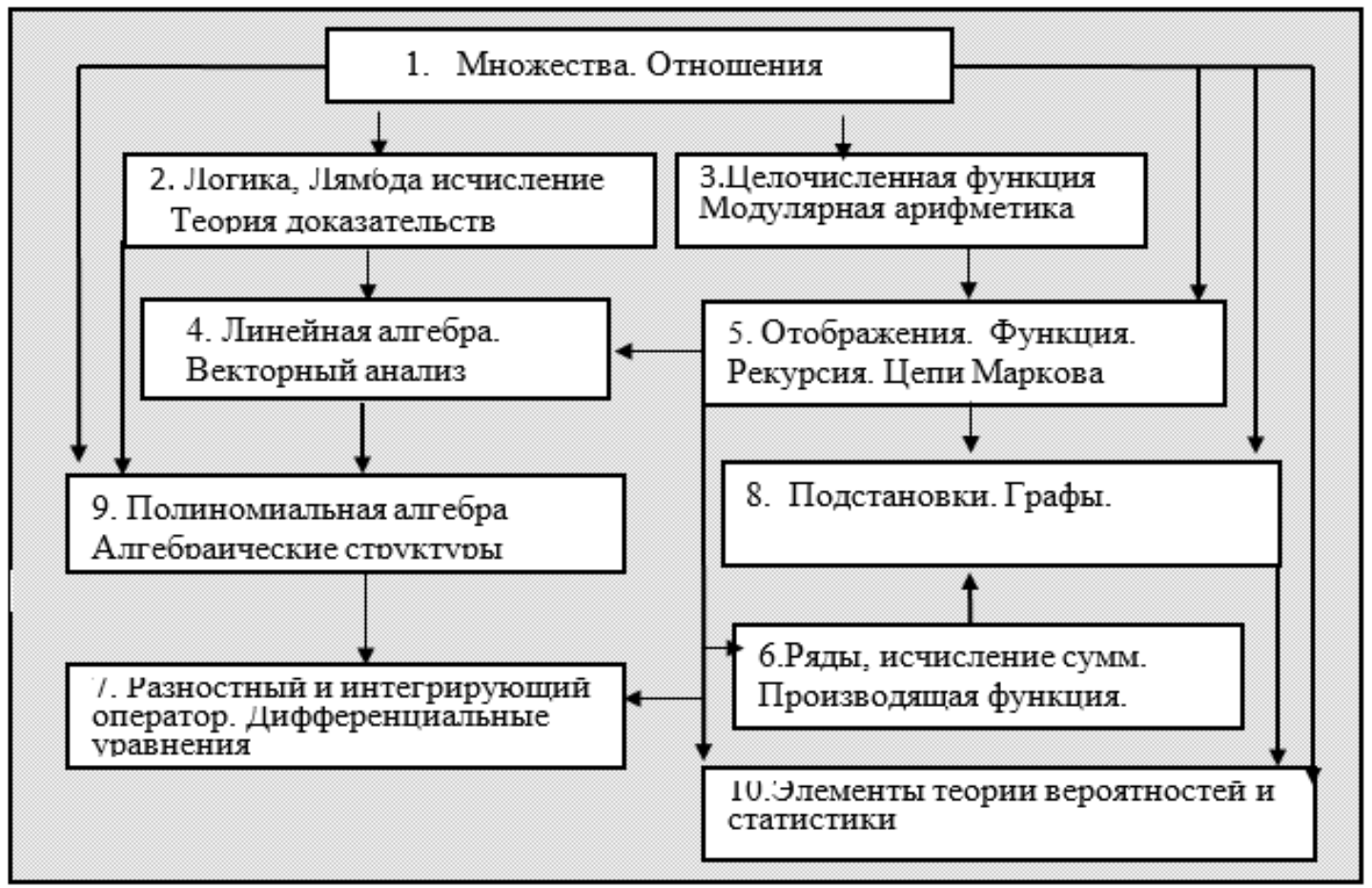

Рис. 1. Структура логических связей содержания курса «Основы математической информатики»

Согласно этапам проектирования методической системы обучения математической информатике и принципу органичного соотношения фундаментальности и практико-ориентированности в обучении будущих бакалавров, в проектировании компетентностно-ориентированного содержания существенна разработка компетентностно-ориентированных задач.

Разработанная модульная программа курса «Основы математической информатики» описывает последовательность изучения модулей, т.е. структурирует содержание образования. Планирование достижения результатов обучения определяется целями освоения каждого отдельного модуля.

\section{Лuтература}

1. Архангельский С. И. Лекции по теории обучения в высшей школе [Текст] / С. И. Архангельский. М.: Высшая школа, 1974, 384 с.

2. Беспалько В. П. Педагогика и прогрессивные технологии обучения [Текст] / В. П. Беспалько. М.: Изд-во Института проф. образования Министерства образования России, 1995,336 с.

3. Бороненко T. А. Методика обучения информатике. Теоретические основы [Текст]: уч. пособ. для студентов / Т.А. Бороненко. СПб., 1997.

4. Даммер М. Д. «Методические основы построения опережающего курса физики основной школы» [Текст]: дис. ... д-ра пед. наук. / М.Д. Даммер. Челябинск, 1997 г.

5. Земиова В.И. Управление учебно-профессиональной деятельностью студентов на основе функционально-деятельностного подходов [Текст]: монография / В. И. Земцова. М.: Компания Спутник, 2008, 208 с.

6. Кнут Д. Искусство программирования для ЭВМ. Т.1: Основные алгоритмы. - М.: Мир, 1976, 736 с

7. Пустобаев В. П. Теория и технология использования средств формализации для информационного моделирования учебного материала [Текст]: дис. ... д-ра пед. наук / В.П. Пустобаев. - М., 2000. - 260 c. 
8. Садулаева Б. С. Использование межпредметных связей курса математики и информатике на факультете информатики [Текст] / Б.С. Садулаева // Математика. Компьютер. Образование: сб. научных трудов: Т. 1 / под ред. Г.Ю. Ризниченко. М.; Ижевск: НИЦ «Регулярная и хаотическая динамика», 2008.

9. Садулаева Б. С. Формирование специальных компетенций будущих бакалавров информатики в процессе обучения математическим основам информатики [Текст]: дисс...к. п .наук / Б.С. Садулаева. Челябинск, 2012.

10. Сухомлин В. А. ИТ-образование. Концепция, образовательные стандарты, процесс стандартизации / В. А. Сухомлин. - М.: Горячая линия. Телеком, 2005, 176 с.

11. Computing Curricula 2001: рекомендации по преподаванию информатики в университетах / пер. с англ. 2002, ЛАНИТ-ТЕРКОМ. СПб., 2002, 372 с. 